Review

\title{
Toll-like receptors and their dual role in periodontitis: a review
}

\author{
Mayank Hans and Veenu Madaan Hans \\ Department of Periodontology, Kalka Dental College and Hospital, Uttar Pradesh, India
}

(Received 30 November 2010 and accepted 12 May 2011)

\begin{abstract}
Innate immunity is the first line of host defense and represents inherited resistance to infection. Innate immunity works through toll-like receptors (TLRs), which recognize the conserved molecular patterns on pathogenic bacteria known as pathogen-associated molecular patterns. The periodontium is a unique environment in which oral microorganisms are in constant contact with the host immune system. The TLRs present on gingival epithelial cells are continuously stimulated, resulting in production of cytokines and defensins that help to maintain oral health. If the epithelial barrier is breached, allowing invasion of bacteria into the underlying connective tissue, the TLRs on other resident and non-resident cells of the periodontium become activated. This leads to an exaggerated release of pro-inflammatory cytokines and other biological mediators, which may cause host tissue destruction. The present review examines the role of TLRs and their signaling in periodontal health and disease. ( $\mathrm{J}$ Oral Sci 53, 263-271, 2011)
\end{abstract}

Keywords: toll-like receptors; pathogenesis; periodontitis; innate immunity.

\section{Introduction}

Innate immunity is the first line of immunological defense. Previously it was thought to involve a nonspecific immune response, but lately it has been recognized

Correspondence to Dr. Mayank Hans, Department of Periodontology, Kalka Dental College and Hospital, Meerut, Uttar Pradesh, India

Tel: +91- 9868151411

Fax: +91- 1352773706

E-mail: mayankhans43@yahoo.com to show remarkable specificity of discrimination between host and pathogens through a sophisticated system based on toll-like receptors (TLRs). These germline-encoded receptors, collectively known as pattern-recognition receptors (PRRs), can detect and respond to conserved and generally distinct microbial structures that are shared by related groups of microorganisms (1). These microbial structures are referred to as pathogen-associated molecular patterns (PAMPs), and include bacterial lipopolysaccharides, peptidoglycan, lipoproteins, bacterial DNA, and double-stranded RNA. Upon interaction with these PAMPs, TLRs activate the innate immune cells through intracellular signaling pathways. This TLRmediated innate immune response is also critical for activation of adaptive immunity. Since periodontitis is a chronic inflammatory disease, TLRs play an important role in its pathogenesis. Recent research has indicated an essential role of these receptors in maintaining the periodontium in a healthy state, as well as in the causation of periodontitis.

\section{History}

Toll-like receptors are so-called because their similarity to the protein encoded by the Toll gene, which was identified in Drosophila in 1985 by Christiane Nüsslein-Volhard (2). The product of the Toll gene was later found to be responsible for dorso-ventral polarity during embryonic development. In 1996, Jules A. Hoffmann et al. demonstrated that Toll plays an essential role in the immunity of Drosophila to fungal infection, which it achieved by activating the synthesis of antimicrobial peptides (3). The first reported human TLR was described by Nomura et al. in 1994 (4), and mapped to a chromosome by Taguchi et al. in 1996 (5). Because, at that time, the immune function of Toll in Drosophila was not known, it was assumed that this TLR (now known as 
TLR1) might participate in mammalian development. In 1997, it was observed that a TLR now known as TLR4 could, when artificially ligated using antibodies, induce the activation of certain genes necessary for initiating an adaptive immune response (6). The association of TLRs with innate immunity was recognized with the discovery of mouse TLR4, which acts as a receptor of bacterial lipopolysaccharide (7). To date, ten human TLRs have been identified, and these are believed to detect a discrete collection of molecules of microbial origin, and to signal the presence of infections.

\section{The toll-like receptor superfamily}

Toll-like receptors, together with the interleukin-1 receptors, form a receptor superfamily known as the "Interleukin-1 Receptor/Toll-Like Receptor Superfamily"; all the members of this family have in common a so-called Toll-IL-1 receptor (TIR) domain. Three subgroups of TIR domains exist. Proteins with subgroup 1 TIR domains are receptors for interleukins that are produced by macrophages, monocytes and dendritic cells, and all have extracellular immunoglobulin (Ig) domains. Proteins with subgroup 2 TIR domains are classical TLRs, and bind directly or indirectly to molecules of microbial origin. A third subgroup of proteins containing TIR domains consists of adaptor proteins that are exclusively cytosolic and mediate signaling from proteins of subgroups 1 and 2 (8).

TLRs are present in vertebrates, as well as in invertebrates. It has been estimated that most mammalian

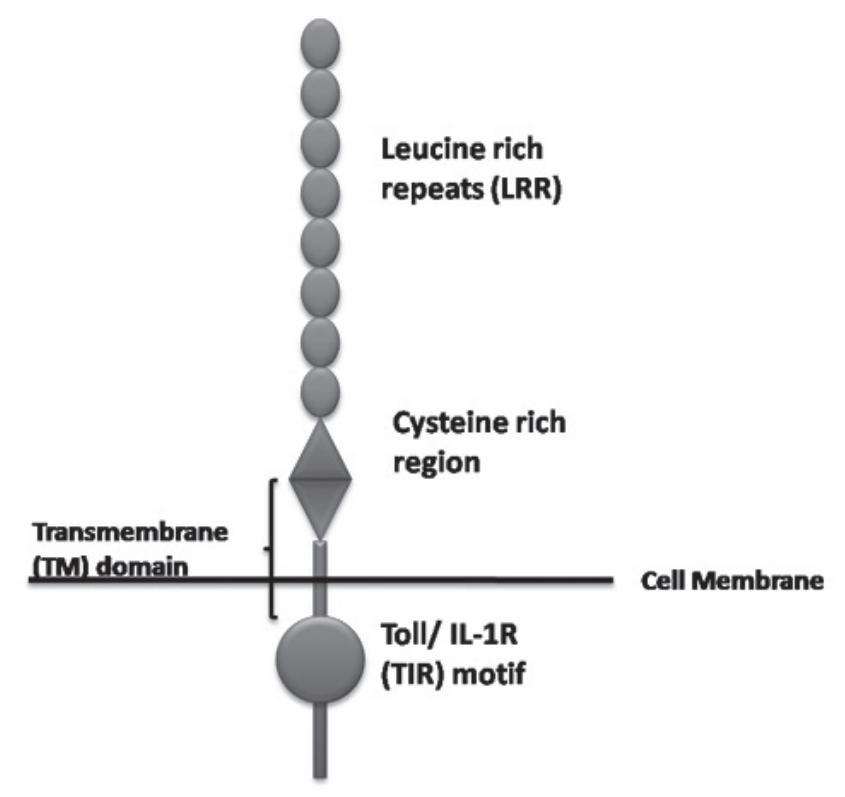

Fig. 1 Structure of a toll-like receptor species have between ten and fifteen types of TLRs. Thirteen TLRs (named simply TLR1 to TLR13) have been identified in humans and mice together, although equivalents of certain TLRs found in humans are not present in all mammals. For example, a gene encoding a protein analogous to TLR10 in humans is present in mice, but appears to have been damaged at some point in the past by a retrovirus (9). On the other hand, mice express TLRs 11, 12, and 13, none of which are represented in humans. Other mammals may express TLRs that are not found in humans.

\section{Structure of the human toll-like receptor}

Human TLRs respond to various PAMPs shared by numerous microorganisms. TLRs are transmembrane glycoproteins possessing varying numbers of extracellular N-terminal leucine-rich repeat (LRR) domain, followed by a cysteine-rich region, a transmembrane domain and a C-terminal cytoplasmic Toll/IL-1R (TIR) domain (10) (Fig. 1). The LRR domain is important for ligand binding and associated signaling, and is a common feature of PRRs. The TIR domain is important in proteinprotein interaction and is typically associated with innate immunity.

\section{Toll-like receptors and their ligands}

Toll-like receptors are primarily expressed by first-line professional phagocytes, i.e. neutrophils, macrophages and dendritic cells. These receptors sense and respond to distinct microbial structures. Toll-like receptors (TLRs 1, $2,4,5$ and 6) that recognize extracellular microbial structures are expressed on the host cell surface; for example, TLR 5 responds to bacterial flagellin. TLR 2 is unique in that it heterodimerizes with the signaling partner TLR1 or TLR6 for detecting and responding to microbial cell wall components. Toll-like receptors (TLRs 3, 7, 8 and 9) specifically detecting viral or bacterial nucleic acids are expressed intracellularly on endocytic vesicles; for example, TLR 3 recognizes double-stranded viral DNA (11). The ligands for human TLRs are enumerated in Table 1.

\section{Expression of toll-like receptors in immune cells}

Toll-like receptors are predominantly expressed on cells of the innate immune system, including neutrophils, monocytes/macrophages, and dendritic cells. These cells express different TLRs, allowing them to induce a wide variety of immune responses to specific pathogens. Neutrophils are the first innate immune cells to migrate to sites of infection and utilize TLRs to recognize and 
Table 1 Ligands for toll-like receptors

\begin{tabular}{ll}
\hline Toll-like receptor & Ligands \\
\hline TLR 1 & Triacyl Lipopeptides \\
TLR 2 & Lipoproteins, Peptidoglycan, Lipoteichoic acid, Zymosan, Porphyromonas gingivalis \\
& lipopolysaccharide \& fimbriae, Capnocytophaga ochracea lipopolysaccharide \\
TLR 3 & Double stranded RNA, Polyinosine-polycytidylic acid \\
TLR 4 & Escherichia coli lipopolysaccharide, Porphyromonas gingivalis lipopolysaccharide, \\
& Actinobacillus actinomycetemcomitans lipopolysaccharide, Fusobacterium nucleatum \\
& lipopolysacchride \\
TLR 5 & Flagellin \\
TLR 6 & Peptidoglycan, Lipoteichoic acid, Diacyl lipopeptides, Zymosan \\
TLR 7 & Imidazquinoline \\
TLR 8 & Single stranded RNA, Imidazquinoline \\
TLR 9 & Bacterial DNA, CpG oligodeoxynucleotide \\
TLR 10 & Not determined \\
\hline
\end{tabular}

Table 2 Toll-like receptors expressed by immune cells

\begin{tabular}{ll}
\hline Cells & Toll like receptors \\
\hline Neutrophils & TLR 1, 2, 4, 5, 6, 7, 8, 9, 10 \\
Monocytes/macrophages & TLR 1, 2, 4, 5, 6, 7, 8 \\
Myeloid dendritic cells & TLR 1, 2, 3, 4, 5, 6, 8, 10 \\
Plasmacytoid dendritic cells & TLR 1, 6, 7, 9 \\
B lymphocytes & TLR 1, 3, 6, 7, 9, 10 \\
T lymphocytes (Th1/Th2) & TLR 2, 3, 5, 9 \\
T lymphocytes (regulatory) & TLR 2, 5, 8 \\
\hline
\end{tabular}

respond to microbial challenge. Neutrophils express TLR 1, TLR 2, and TLRs 4 to 10, but not TLR 3 (12). Macrophages/monocytes, also the first line of defense, bind to microbial pathogens through TLRs. They play a key role in host defense by recognizing, engulfing and killing microorganisms. The binding of PAMPs to monocyte TLRs can influence the type of adaptive immune response (13).

Recent research has clarified that adaptive immunity did not evolve to replace innate immunity, but rather evolved around it. Development of adaptive immunity is controlled through activation of innate immune cells, especially antigen-presenting dendritic cells. TLRs of resident immature dendritic cells detect the PAMPs and transmit the information through signaling pathways, resulting in activation of dendritic cells. This activation results in production of cytokines and chemokines critical for T-cell priming and differentiation (14). Two subpopulations of dendritic cell precursors have been identified in human blood: myeloid dendritic cells and plasmacytoid dendritic cells expressing different TLRs.

It is evident that both $\mathrm{B}$ and $\mathrm{T}$ lymphocytes are present in diseased periodontal tissue. It has been hypothesized that $\mathrm{T}$ cells predominate in stable periodontal lesions, while the proportion of B cells and plasma cells is increased in progressive lesions. More recently, it has been shown that TLRs are also expressed on the cells responsible for adaptive immunity, i.e. B and T lymphocytes. The TLRs expressed on $\mathrm{T}$ lymphocytes and their respective ligands can directly modulate $\mathrm{T}$ cell function. These TLRs act as co-stimulatory receptors to enhance proliferation and/ or cytokine production of T-cell receptor-stimulated $\mathrm{T}$ lymphocytes. Also, TLRs on CD25+CD4+ regulatory $\mathrm{T}$ cells are thought to modulate their suppressive activity (15). TLRs expressed by all of these immune cells are listed in Table 2.

\section{Toll-like receptors in periodontal tissues}

Research has established that along with immune cells, TLRs are also expressed in periodontal tissues (16-21). Since the gingiva is constantly exposed to microbes present in plaque biofilm, TLR signaling plays an important role in the innate immune response and maintenance of periodontal health. However, over-production of proinflammatory cytokines due to chronic stimulation of TLRs may lead to tissue destruction. The TLRs present on different periodontal cells are listed in Table 3.

\section{Toll-like receptor signaling}

Toll-like receptor signaling takes place by two separate pathways: the myeloid differentiation primary 
Table 3 Toll-like receptors in periodontal tissues

\begin{tabular}{|c|c|c|}
\hline Periodontal Cells & Toll-like receptors & Function \\
\hline Gingival Epithelial cells & TLR $2,3,4,5,6,9$ & $\begin{array}{l}\text { Increased attachment and migration of leucocytes towards antigen on } \\
\text { lumen of the pocket, also induces production of Interleukin- } 8 \text { (IL-8) as } \\
\text { well as Matrix metalloproteinases. }\end{array}$ \\
\hline Gingival fibroblasts & TLR $2,4,9$ & $\begin{array}{l}\text { Increased production of Interleukin- } 8 \text { as well as other pro-inflammatory } \\
\text { cytokines. }\end{array}$ \\
\hline Endothelium & TLR $1,3,4,5$ & $\begin{array}{l}\text { Production of pro-inflammatory cytokines and chemokines, migration of } \\
\text { immune cells towards gingival sulcus. }\end{array}$ \\
\hline Osteoblasts & TLR $1,4,5,6,9$ & $\begin{array}{l}\text { Upregulation of pro-inflammatory cytokines like IL- } 8 \text {, Tumour necrosis } \\
\text { factor- } \alpha(\mathrm{TNF}-\alpha) \text { and biologic mediators responsible for bone resorption. } \\
\text { Increased expression of receptor activator of nuclear factor } \kappa \text { B ligand } \\
\text { (RANKL). }\end{array}$ \\
\hline Osteoclasts & TLR 2, 4 & Enhanced survival of osteoblasts and increased osteoclastic activities. \\
\hline Cementoblasts & TLR 2, 4 & Down regulation of RANKL \\
\hline $\begin{array}{l}\text { Periodontal ligament } \\
\text { fibroblasts }\end{array}$ & TLR 2, 4 & $\begin{array}{l}\text { Enhanced production of pro-inflammatory cytokines, release of proteases } \\
\text { causing direct destruction of surrounding tissues. }\end{array}$ \\
\hline
\end{tabular}

response protein 88 (MyD88)-dependent pathway and the MyD88- independent pathway (22). The MyD88dependent pathway is essential for most TLR-mediated cell activation, whereas stimulation of TLR 3 and 4 takes place through the MyD88-independent pathway (Fig. 2).

In the MyD88-dependent pathway, TLR signaling is mediated by adaptor molecule MyD88, which either alone or in combination with another adaptor protein, Toll-IL-1 receptor domain-containing adaptor protein (TIRAP), activates interleukin-1 receptor-associated kinase-4 (IRAK-4). This IRAK-4 then unites with tumor necrosis factor receptor-associated factor 6 (TRAF6), leading to activation of two distinct signaling pathways. One pathway leads to activation of activator protein 1 (AP-1) through activation of mitogen-activated protein kinase (MAK). The other pathway activates transforming growth factor- $\beta$-activated kinase 1 (TAK1), which enhances the activity of inhibitor of the nuclear factor- $\kappa \mathrm{B}$ kinase complex. This leads to degradation of the inhibitor of nuclear factor- $\kappa \mathrm{B}$ and release of nuclear factor- $\kappa \mathrm{B}$ $(\mathrm{NF}-\mathrm{kB})$, which translocates to the nucleus. Both the end products of these signaling pathways, AP- 1 and NF- $\mathrm{kB}$, induce the expression of pro-inflammatory cytokines and chemokines.

TLR 7, 8 and 9 recognize viral nucleic acid through another pathway, which is also MyD88-dependent. MyD88 associates with interleukin-1 receptor associated kinase-1 (IRAK1), which in turn phosphorylates interferon-regulatory factor-7 (IRF7). The phosphorylated IRF7 translocates to the nucleus and regulates the expression of type I interferon. TLR signaling through the MyD88-independent pathway results in induction of type 1 interferon through interferon-regulatory factor-3
(IRF-3). The adaptor molecules for this pathway are Toll-IL-1 receptor domain-containing adaptor inducing interferon- $\beta$ (TRIF) and TRIF-related adaptor molecules (TRAM).

\section{Specificity of innate immunity}

Until recently, the innate immune response was viewed as non-specific and a temporary expedient to 'buy time' until the activation of adaptive immunity, which comprises the B and $\mathrm{T}$ lymphocyte systems, each of which expresses antigen receptors of strict specificity (23). Although innate immunity is unable to make fine structural distinctions, it is endowed with considerable specificity. This specificity occurs due to a collection of receptors and their specific ligands that have evolved to allow rapid identification and response to non-self. These receptors, collectively known as PRRs, can detect and respond to conserved and generally distinct microbial structures that are shared by related groups of microorganisms (24). Toll-like pattern recognition receptors recognize different molecular components, thereby activating different innate pathways. This activation involves expression of co-stimulatory molecules and production of cytokines and chemokines which are critical for T-cell priming and differentiation. It is now recognized that immune cells release quantitatively and qualitatively different cytokines on stimulation with gram-positive and gram-negative bacteria, indicating the specificity of the response (25).

Innate immunity also faces the challenge of discriminating the host from among a large number of periodontal pathogens using a limited number of cell surface receptors. One complicating factor is that microorganisms have 




Fig. 2 Toll-like receptor signaling.

TLR: toll-like receptor; MyD88: myeloid differentiation primary response protein 88; TIRAP: toll-IL-1 receptor domain-containing adaptor protein; IRAK-1: interleukin 1 receptor-associated kinase-1; IRAK-4: interleukin 1 receptor-associated kinase-4; TRAF6: tumor necrosis factor receptor-associated factor 6; MAK: mitogen-activated protein kinase; AP-1: activator protein 1; TAK1: transforming growth factor- $\beta$-activated kinase 1 ; NF- $\mathrm{kB}$ : nuclear factor- $\mathrm{\kappa B}$; IRF-3: interferon-regulatory factor-3; IRF-7: interferon-regulatory factor-7; TRIF: Toll-IL-1 receptor domain-containing adaptor inducing interferon- $\beta$; TRAM: TRIF-related adaptor molecules, $\bullet$ phosphorylation

the ability to mutate in order to escape host recognition. Innate immunity meets this challenge through recognition of evolutionarily conserved structures - known as PAMPs - on pathogens that are not present in higher eukaryotes. These play a role in the ability of pathogens to evade host defense, and are therefore not subject to high mutation rates. These PAMPs are shared among pathogens but are not expressed by the host (26). Thus, a limited number of receptors are able to recognize a large number of pathogens.

Also, recent information suggests that a specific TLRmediated signaling pathway differentially select adaptors to initiate the MyD88-dependent or independent pathway. As discussed above, only four adaptor molecules have been identified for both of these pathways: Myeloid differentiation primary response protein 88 (MyD88), Toll-IL-1 receptor domain-containing adaptor protein (TIRAP), Toll-IL-1 receptor domain-containing adaptor 
inducing interferon- $\beta$ (TRIF), and TRIF-related adaptor molecules (TRAM). The response of a limited number of TLRs to an extensive number of PAMPs through only four adaptor molecules indicates differential signaling to different PAMPs. Thus, clusters of many genes must be selectively regulated to control needed immune processes (27).

\section{Role of toll-like receptors in periodontal health and disease}

The periodontium is continually exposed to dental plaque, which harbors many commensal and pathogenic oral microorganisms. Periodontal tissues express different types of TLRs, allowing them to actively participate in the innate immune response against these oral microorganisms. Thus, these TLRs provide first line of defense in maintaining periodontal health.

It has been suggested recently that the oral mucosa develops tolerance after repeated exposure to bacterial products (28). Down-regulation of TLR expression and inhibition of intracellular signaling may be the underlying mechanisms of tolerance. However, recent research has indicated that under steady-state conditions, activation of TLRs by commensal bacteria is critical for the maintenance of oral health. Gingival epithelial cells express TLR 2, 3, 4, 5, 6 and 9 and recognize various microorganisms with the help of these receptors (16). These TLRs expressed on gingival epithelium continually interact with oral microorganisms that form biofilms on tooth surfaces. This TLR signaling results in innate immune responses involving the release of the antibacterial $\beta$-defensins cathelicidin and calprotectin, as well as neutrophil chemoattractant (interleukin-8) (29). Therefore, TLR signaling limits microbial invasion and prevents commensal organisms from breaching the epithelial barrier, thereby maintaining gingival health. Further investigations are required to better understand the interaction between oral microorganisms and gingival epithelial cells, and how the periodontium prevents disease initiation and progression through TLR signaling.

Periodontal health represents a dynamic state in which pro-inflammatory and anti-microbial activities for control of infection are optimally balanced by anti-inflammatory mechanisms to prevent unwarranted inflammation. This

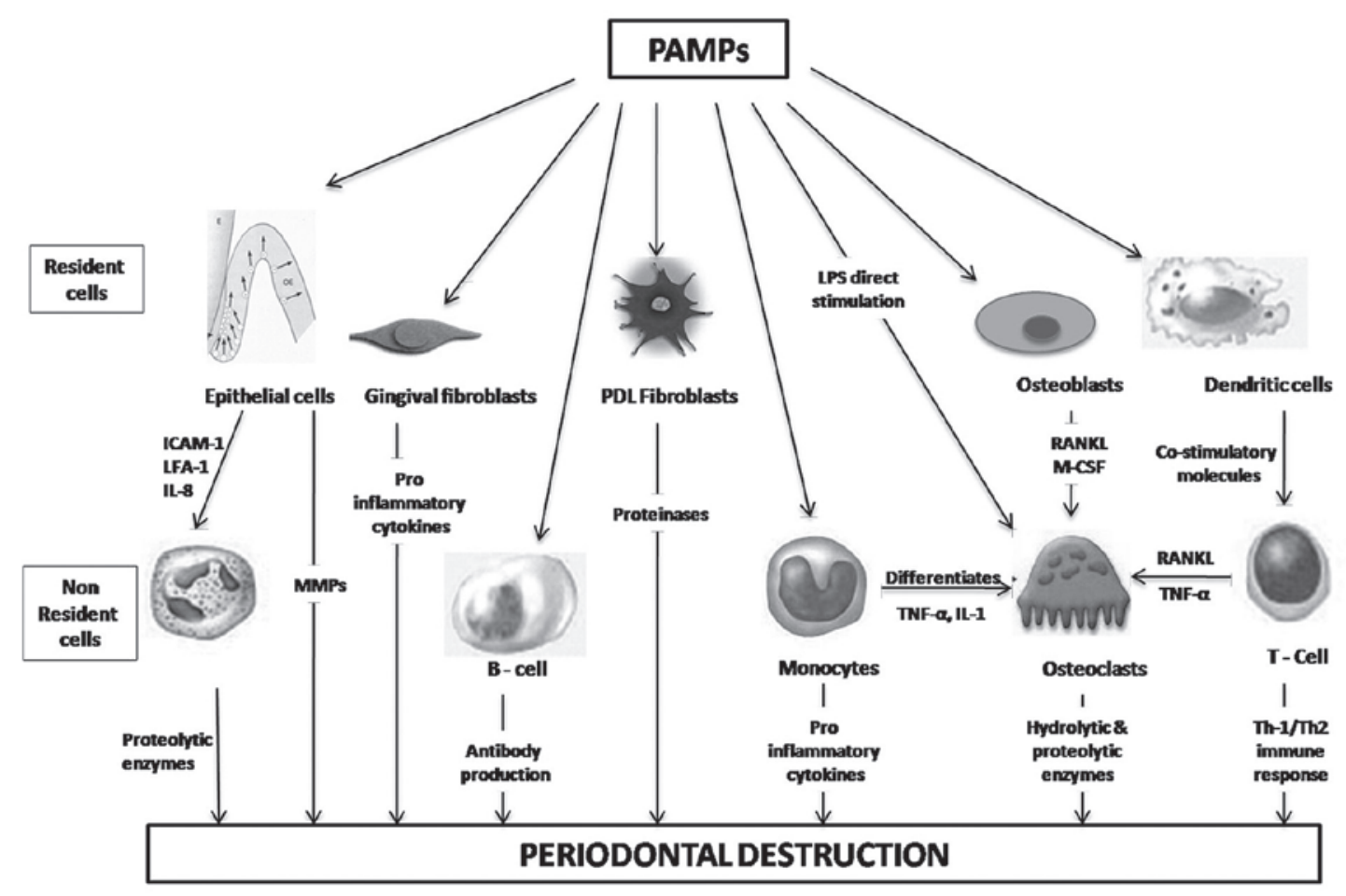

Fig. 3 TLR-mediated effects of PAMPs on cells of the periodontium and their interactions.

ICAM-1: intercellular adhesion molecule-1; LFA-1: ligand for lymphocyte function-associated antigen-1; IL-8: interleukin-8; MMPs: matrix metalloproteinases; PDL: periodontal ligament; LPS: bacterial lipopolysaccharides; TNF- $\alpha$ : tumor necrosis factor- $\alpha$; IL-1: interleukin-1; RANKL: receptor activator of nuclear factor kappa B ligand; M-CSF: macrophage colonystimulating factor 
homeostasis is disrupted when pathogens present in dental plaque undermine the host defense mechanism. Chronic stimulation of TLRs in periodontal tissues by bacterial PAMPs can lead to excessive production of pro-inflammatory mediators, resulting in tissue destruction. Also, periodontitis induced by bacterial plaque may start with disruption and penetration of the gingival epithelial barrier by invasive bacteria or their cytotoxic products. Through this invasion into deeper tissues, TLRs in other cells such as macrophages, fibroblasts, osteoblasts, osteoclasts and antigen-presenting cells become activated. These cells, when stimulated, produce various pro-inflammatory cytokines that lead to inflammation and immune cell infiltration. The infiltrated cells, such as memory T-cells, further produce cytokines and amplify the inflammatory reaction, leading to destruction of connective tissue and bone (30). Thus, TLRs act as a double-edged sword, not only maintaining periodontal health but also contributing to periodontal tissue destruction.

\section{Toll-like receptor-mediated progression of periodontal disease}

The first cells to respond to PAMPs are the epithelial cells lining the sulcus. These cells express intercellular adhesion molecule-1 (ICAM-1) and the ligand for lymphocyte function-associated antigen-1 (LFA-1), which interact with and direct the attachment and migration of leucocytes towards the gingival sulcus. Interleukin-8 (IL-8), a known neutrophil chemoattractant, is also released by epithelial cells, further enhancing the migration of neutrophils $(31,32)$. Epithelial cells are also known to produce matrix metalloproteinases (MMPs) in response to PAMPs, causing direct damage to periodontal tissues (33). MMPs are a structurally related group of endopeptidases collectively capable of degrading practically all extracellular matrix and basement membrane components. Once the epithelial cells are activated, they mediate the activation of other resident as well as non-resident cells. When stimulated via TLRs, neutrophils exhibit increased chemotaxis as well as production of pro-inflammatory cytokines [interleukin-1 (IL-1); interleukin-6 (IL-6); tumor necrosis factor- $\alpha(\mathrm{TNF}-\alpha)]$ (34). These cytokines play a central role in periodontal tissue destruction. The properties of these cytokines that relate to tissue destruction involve stimulation of bone resorption and induction of tissuedegrading proteinases. The IL- 8 secreted by epithelial cells stimulates the endothelial cells lining the blood vessels through TLR-4, leading to increased adhesion of monocytes by increased expression of the adhesion molecules E-selectin, ICAM-1 and vascular cell adhesion molecule-1 (VCAM-1) (35). When exposed to PAMPs, monocytes produce pro-inflammatory cytokines and may differentiate into osteoclasts upon direct stimulation with bacterial lipopolysaccharides with the help of receptor activator of nuclear factor $\mathrm{\kappa B}$ ligand (RANKL) $(36,37)$. Dendritic cells are resident immune cells present in both epithelium and connective tissue. TLRs present on these cells induce their maturation when stimulated with PAMPs. When activated, these cells not only act as antigen-presenting cells but also produce cytokines and co-stimulatory molecules that activate T-lymphocytes to produce a Th1 or Th2 immune response (38) (Fig. 3).

As the epithelial barrier is breached, microorganisms and their products access gain to the underlying connective tissue and directly activate the cells present there. Once stimulated by PAMPs, gingival fibroblasts produce pro-inflammatory cytokines leading to tissue destruction and bone resorption. Periodontal ligament fibroblasts, on the other hand, produce proteinases on TLR stimulation, resulting in direct degradation of periodontal tissues (39). With the PAMPs entering the circulation via blood vessels in connective tissue, lymphocytes move toward the site of infection. In the presence of biological mediators, naïve T-cells differentiate and initiate a Th1 or Th2 immune response, TLRs on T cells acting as type of co-stimulatory molecule (15). B lymphocytes are transformed into plasma cells, which produce antibodies against bacterial antigens. Osteoblasts also react to PAMPs through TLRs and produce biological mediators (MMPs, prostaglandin E2) responsible for bone resorption (40). Osteoblasts, marrow stromal cells, and T and B cells express RANKL, which is essential for activation of osteoclasts. RANKL in the presence of macrophage colony-stimulating factor (M-CSF) attaches to receptor activator of nuclear factor $\kappa B($ RANK) present on osteoclasts and osteoclast precursors, and activates them (41). A bone-protecting factor, osteoprotegrin (OPG), produced by osteoblasts and bone marrow stomal cells, inhibits the RANK/RANKL interaction and prevents bone resorption (42). If the destructive process continues, more subgingival plaque tends to accumulate, connective tissue attachment to the tooth is destroyed, epithelial cells proliferate apically along the root surface, and the periodontal pocket deepens. If not controlled, the bone and attachment loss extends to the apex, and the tooth is ultimately lost.

Toll-like receptor signaling at the dento-epithelial junction is critical in maintaining periodontal health as well as in the progression of periodontitis. However, there are still gaps in our knowledge of the mechanisms 
by which TLRs maintain periodontal health and what leads to bacterial immune evasion and disease progression. At present it is uncertain which specific signaling pathways need to be blocked to attenuate the pathology or enhanced to promote host defense. Therefore, further investigations are required in this field to understand the initiation and progression of periodontal disease and develop therapeutic interventions to control it.

\section{References}

1. Takeda K, Akira S (2005) Toll-like receptors in innate immunity. Int Immunol 17, 1-14.

2. Hansson GK, Edfeldt K (2005) Toll to be paid at the gateway to the vessel wall. Arterioscler Thromb Vasc Biol 25, 1085-1087.

3. Lemaitre B, Nicolas E, Michaut L, Reichhart JM, Hoffmann JA (1996) The dorsoventral regulatory gene cassette spätzle/Toll/cactus controls the potent antifungal response in Drosophilia adults. Cell 86, 973-983.

4. Nomura N, Miyajima N, Sazuka T, Tanaka A, Kawarabayasi Y, Sato S, Nagase T, Seki N, Ishikawa K, Tabata S (1994) Prediction of the coding sequences of unidentified human genes. I. The coding sequences of 40 new genes (KIAA0001-KIAA0040) deduced by analysis of randomly sampled cDNA clones from human immature myeloid cell line KG-1. DNA Res 1, 27-35.

5. Taguchi T, Mitcham JL, Dower SK, Sims JE, Testa JR (1996) Chromosomal localization of TIL, a gene encoding a protein related to the Drosophila transmembrane receptor Toll, to human chromosome 4p14. Genomics 32, 486-488.

6. Medzhitov R, Preston-Hurlburt P, Janeway CA Jr (1997) A human homologue of the Drosophila Toll protein signals activation of adaptive immunity. Nature 388, 394-397.

7. Poltorak A, He X, Smirnova I, Liu MY, Van Huffel C, Du X, Birdwell D, Alejos E, Silva M, Galanos C, Freudenberg M, Riccardi-Castagnoli P, Layton B, Beutler B (1998) Defective LPS signaling in $\mathrm{C} 3 \mathrm{H} / \mathrm{HeJ}$ and $\mathrm{C} 57 \mathrm{BL} / 10 \mathrm{ScCr}$ mice: mutations in Tlr4 gene. Science 282, 2085-2088.

8. Dunne A, O'Neill LAJ (2003) The interleukin-1 receptor/Toll-like receptor superfamily: signal transduction during inflammation and host defense. Sci STKE 171, re3.

9. Hasan U, Chaffois C, Gaillard C, Saulnier V, Merck $\mathrm{E}$, Tancredi S, Guiet $\mathrm{C}$, Brière F, Vlach J, Lebecque S, Trinchieri G, Bates EE (2005) Human TLR10 is a functional receptor, expressed by B cells and plasmacytoid dendritic cells, which activates gene transcription through MyD88. J Immunol 174, 2942-2950.

10. Jin MS, Kim SE, Heo JY, Lee ME, Kim HM, Paik SG, Lee H, Lee JO (2007) Crystal structure of the TLR1-TLR2 heterodimer induced by binding of a tri-acylated lipopeptide. Cell 130, 1071-1082.

11. Kline KA, Fälker S, Dahlberg S, Normark S, Henriques-Normark B (2009) Bacterial adhesions in host-microbe interactions. Cell Host Microbe 5, 580-592.

12. Hayashi F, Means TK, Luster AD (2003) Toll-like receptors stimulate human neutrophil function. Blood 102, 2660-2669.

13. Iwasaki A, Medzhitov R (2004) Toll-like receptor control of the adaptive immune responses. Nat Immunol 5, 987-995.

14. Hornung V, Rothenfusser S, Britsch S, Krug A, Jahrsdörfer B, Giese T, Endres S, Hartmann G (2002) Quantitative expression of toll-like receptor 1-10 mRNA in cellular subsets of human peripheral blood mononuclear cells and sensitivity to $\mathrm{CpG}$ oligodeoxynucleotides. J Immunol 168 , 4531-4537.

15. Kabelitz D (2007) Expression and function of Toll-like receptors in T lymphocytes. Curr Opin Immunol 19, 39-45.

16. Kusumoto Y, Hirano H, Saitoh K, Yamada S, Takedachi M, Nozaki T, Ozawa Y, Nakahira Y, SahoT, OgoH, Shimabukuru Y, Okada H, Murakami S (2004) Human gingival epithelial cells produce chemotactic factors interleukin- 8 and monocyte chemoattractant protein-1 after stimulation with Porphyromonas gingivalis via toll-like receptor 2 . J Periodontol 75, 370-379.

17. Tabeta K, Yamazaki K, Akashi S, Miyake K, Kumada H, Umemoto T, Yoshie H (2000) Toll-like receptors confer responsiveness to lipopolysaccharide from Porphyromonas gingivalis in human gingival fibroblasts. Infect Immun 68, 3731-3735.

18. Nociti FH Jr, Foster BL, Barros SP, Darveau RP, Somerman MJ (2004) Cementoblast gene expression is regulated by Porphyromonas gingivalis lipopolysaccharide partially via toll-like receptor-4/MD-2. J Dent Res 83, 602-607.

19. Asai Y, Hirokawa Y, Niwa K, Ogawa T (2003) Osteoclast differentiation by human osteoblastic cell line SaOS-2 primed with bacterial lipid A. FEMS Immunol Med Microbiol 38, 71-79.

20. Itoh K, Udagawa N, Kobayashi K, Suda K, Li X, 
Takami M, Okahashi N, Nishihara T, Takahashi N (2003) Lipopolysaccharide promotes the survival of osteoclasts via Toll-like receptor 4, but cytokine production of osteoclasts in response to lipopolysaccharide is different from that of macrophages. J Immunol 170, 3688-3695.

21. Hatakeyama J, Tamai R, Sugiyama A, Akashi S, Sugawara S, Takada H (2003) Contrasting responses of human gingival and periodontal ligament fibroblasts to bacterial cell-surface components through the CD14/Toll-like receptor system. Oral Microbiol Immunol 18, 14-23.

22. O'Neill LA (2008) When signaling pathways collide: positive and negative regulation of toll-like receptor signal transduction. Immunity 29, 12-20.

23. Fearon DT (1997) Seeking wisdom in innate immunity. Nature 388, 323-324.

24. Medzhitov R (2007) Recognition of microorganisms and activation of the immune response. Nature 449, 819-826.

25. Newman MG, Takei HH, Klokkevold PR, Carranza FA (2006) Carranza's clinical periodontology. 10th ed, Saunders, St Louis, 259-274.

26. Medzhitov R (2001) Toll-like receptors and innate immunity. Nat Rev Immunol 1, 135-145.

27. Akira S, Takeda K, Kaisho T (2001) Toll-like receptors: critical proteins linking innate and acquired immunity. Nat Immunol 2, 675-680.

28. Muthukuru M, Jotwani R, Cutler CW (2005) Oral mucosal endotoxin tolerance induction in chronic periodontitis. Infect Immun 73, 687-694.

29. Weinberg A, Krisanaprakornkit S, Dale BA (1998) Epithelial antimicrobial peptides: review and significance for oral applications. Crit Rev Oral Biol Med 9, 399-414.

30. Page RC, Offenbacher S, Schroeder HE, Seymour GJ, Kornman KS (1997) Advances in the pathogenesis of periodontitis: summary of developments, clinical implications and future directions. Periodontol 2000 14, 216-248.

31. Yan P, Yue J, Jiang H (1999) Expression of ICAM-1/LFA-1 in the pocket area of adult periodontitis. Zhonghua Kou Qiang Yi Xue Za Zhi 34, 106-108. (in Chinese)

32. Han YW, Shi W, Huang GT, Kinder Haake S, Park NH, Kuramitsu H, Genco RJ (2000) Interactions between periodontal bacteria and human oral epithelial cells: Fusobacterium nucleatum adheres to and invades epithelial cells. Infect Immun 68, 3140-3146.

33. Warner RL, Bhagavathula N, Nerusu KC, Lateef
H, Younkin C, Johnson KJ, Varani J (2004) Matrix metalloproteinases in acute inflammation: induction of MMP-3 and MMP-9 in fibroblasts and epithelial cells following exposure to proinflammatory mediators in vitro. Exp Mol Pathol 76,189-195.

34. Trevani AS, Chorny A, Salamone G, Vermeulen M, Gamberale R, Schettini J, Raiden S, Geffner J (2003) Bacterial DNA activates human neutrophils by a CpG-independent pathway. Eur J Immunol 33, 3164-3174.

35. Galdiero M, de l'Ero GC, Marcatili A (1997) Cytokine and adhesion molecule expression in human monocytes and endothelial cells stimulated with bacterial heat shock proteins. Infect Immun 65, 699-707.

36. Hartmann G, Krieg AM (1999) CpG DNA and LPS induce distinct patterns of activation in human monocytes. Gene Ther 6, 893-903.

37. Jiang Y, Mehta CK, Hsu TY, Alsulaimani FF (2002) Bacteria induce osteoclastogenesis via an osteoblast-independent pathway. Infect Immun 70, 3143-3148.

38. Krieg AM (2002) CpG motifs in bacterial DNA and their immune effects. Annu Rev Immunol 20, 709-760.

39. Hatakeyama J, Tamai R, Sugiyama A, Akashi S, Sugawara S, Takada H (2003) Contrasting responses of human gingival and periodontal ligament fibroblasts to bacterial cell-surface components through the CD14/toll-like receptor system. Oral Microbiol Immunol 18, 14-23.

40. Pelt P, Zimmermann B, Ulbrich N, Bernimoulin JP (2002) Effects of lipopolysaccharide extracted from Prevotella intermedia on bone formation and on the release of osteolytic mediators by fetal mouse osteoblasts in vitro. Arch Oral Biol 47, 859-866.

41. Lerner UH (2004) New molecules in the tumor necrosis factor ligand and receptor superfamilies with importance for physiological and pathological bone resorption. Crit Rev Oral Biol Med 15, 64-81.

42. Simonet WS, Lacey DL, Dunstan CR, Kelley M, Chang MS, Lüthy R, Nguyen HQ, Wooden S, Bennett L, Boone T, Shimamoto G, DeRose M, Elliott R, Colombero A, Tan HL, Trail G, Sullivan J, Davy E, Bucay N, Renshaw-Gegg L, Hughes TM, Hill D, Pattison W, Campbell P, Sander S, Van G, Tarpley J, Derby P, Lee R, Boyle WJ (1997) Osteoprotegerin: a novel secreted protein involved in the regulation of bone density. Cell 89, 309-319. 